\title{
EDUCAÇÃO E DESENVOLVIMENTO SOCIOTERRITORIAL NO PRONERA
}

Rodrigo Simão Camacho

Universidade Federal da Grande Dourados - UFGD, Dourados, MS. E-mail: rodrigocamacho@ufgd.edu.br

\section{RESUMO}

Os movimentos sociais camponeses, por meio de sua luta, conquistaram um modelo de educação fundado em princípios e práticas sustentáveis de produção e organização social. Dessa forma, o principal objetivo deste artigo é analisar o desenvolvimento territorial promovido pelo Programa Nacional de Educação na Reforma Agrária (PRONERA). Para escrever este artigo, como um primeiro passo, nós revisamos a literatura sobre Educação do Campo dialogando, sobretudo, com o Manual de Operações do PRONERA publicado em 2011. Tendo em vista a formação de milhares de jovens no campo, podemos afirmar que o programa tem ajudado a construir outra forma de desenvolvimento territorial em espaços rurais com base na equidade e sustentabilidade.

Palavras-chave: Educação do Campo, PRONERA, Desenvolvimento Territorial, Equidade Social.

\section{EDUCATION AND SOCIOTERRITORIAL DEVELOPMENT IN PRONERA}

\begin{abstract}
The peasant struggle for land by peasant social movements construction of an educational model based on sustainable principles and practices of production and social organization. Thus, the main objective of this paper is to analyze the experience of integration between education and sustainability, in the National Education Program in Agrarian Reform (PRONERA). To write this article, as a first step, we review the literature on Education of the countryside dialogue, especially with the Operations Manual PRONERA published in 2011. Given the formation of thousands of young people in the countryside, we can say that the program has helped to build another form of territorial development in rural areas based on equity and sustainability.
\end{abstract}

Keywords: Education of the Countryside, PRONERA, Territorial Development, Social Equity. 


\section{INTRODUÇÃO}

Existe uma desigualdade educacional no tocante aos moradores das áreas rurais brasileiras. A fim de ser combatida, essa desigualdade exige políticas específicas destinadas a melhorar a educação praticada no campo. Estas políticas têm de ter em conta as particularidades dos sujeitos do campo, bem como, o seu modo de vida.

A Educação do Campo emerge como uma importante oportunidade para desenvolver os territórios dos camponeses, cujo modelo de produção baseado nas culturas alimentares básicas de maneira agroecológica, se mostra como uma alternativa ao modelo hegemônico vigente do agronegócio, garantindo a Soberania Alimentar. O Programa Nacional de Educação na Reforma Agrária (PRONERA) é um exemplo importante de Educação do Campo na esfera da política pública. Este programa foi criado no Brasil em 1998, como uma resposta aos esforços do movimento social e representantes de sindicatos rurais. O PRONERA pode ser considerado uma experiência inovadora, uma vez que foi implantado em um território que tem sido historicamente marcada pela exclusão social e pela ausência de políticas públicas na área da educação. Seu principal objetivo é fortalecer ambientes rurais como território de vida em todas as suas dimensões: econômica, social, política, cultural e ético. Tendo em vista a formação de milhares de jovens no campo, podemos afirmar que o programa tem ajudado a construir outra forma de desenvolvimento territorial em espaços rurais com base na equidade e sustentabilidade (BRASIL, 2011; CAMACHO, 2014).

\section{METODOLOGIA}

Para escrever este artigo, como um primeiro passo, nós revisamos a literatura sobre Educação do Campo dialogando, sobretudo, com o Manual de Operações do Programa Nacional de Educação na Reforma Agrária (PRONERA) publicado em 2011. O segundo passo foi à busca de dados com relação à situação educacional dos habitantes do campo, antes e depois, do PRONERA.

\section{HISTÓRICO DA EDUCAÇÃO DO CAMPO NO BRASIL}

A criação de um novo projeto de Educação do Campo está relacionada com os esforços conjuntos de algumas entidades que formaram a Articulação Nacional em 1998, em favor da Educação Básica no Campo. As entidades que promoveram este movimento foram: a Conferência Nacional dos Bispos do Brasil (CNBB), o Movimento dos Trabalhadores Sem Terra (MST), Fundo das Nações Unidas para a Infância (UNICEF), Organização das Nações Unidas para a Educação, a Ciência e a Cultura (UNESCO), da Universidade de Brasília (UNB) e o Grupo de Trabalho da Reforma Agrária (GTRA). A primeira conferência chamada "Por uma Educação Básico do Campo" ocorreu em Luziânia - GO, em 1998.

A primeira razão por trás da luta pela Educação do Campo no Brasil é a realidade existente de exclusão com relação aos habitantes do campo. A falta de acesso a uma educação que permita o desenvolvimento das comunidades no campo está relacionada com a história da estrutura agrária no Brasil baseada no latifúndio e na desterritorialização dos indígenas de suas terras tradicionais e das populações camponesas de sua terra de trabalho (CAMACHO et al., 2015). A realidade para os povos do campo tem sido sempre de uma educação que não ultrapassa as séries iniciais do ensino fundamental. Há ainda um grande número de analfabetos no campo. A educação sempre foi inacessível para estas populações excluídas. A leitura e a escrita são instrumentos de status e poder dentro de uma sociedade capitalista e são geralmente um privilégio das classes dominantes. Assim, as classes subalternas têm poucas oportunidades para dominar os códigos de culturas letradas (CAMACHO, 2014).

Uma pesquisa por amostragem realizada pelo Instituto Nacional de Colonização e Reforma Agrária (INCRA), em 2010, revelou que o acesso à educação continua sendo um grande desafio para populações rurais estabelecidas em todas as regiões do país. No que diz respeito aos 
dados sobre o ensino superior no Brasil, a região Norte tem 390.752 famílias assentadas, e menos de $1 \%$ com ensino superior concluído. A região Nordeste tem 302.513 famílias assentadas, mas menos de $1 \%$ tem diploma universitário. A região Centro-Oeste tem 138.000 famílias assentadas, destes, $1 \%$ possuem nível superior, e 1,33\% estão estudando. A região Sudeste tem 40.156 famílias assentadas, destes, 1,01\% tem curso superior concluído, e 1,16\% estão estudando. A região Sul tem 34.991 famílias assentadas: menos de 1\% com diploma universitário, e 1,09\% estão estudando (BRASIL, 2011).

Apesar de estudos e dados do censo mostrar uma expansão quantitativa no acesso escolar, as desigualdades sociais e regionais, bem como os níveis de analfabetismo, ainda são altos, especialmente, nas regiões Norte e Nordeste (PAIVA, 2004). De acordo com Andrade e Di Pierro (2004), aproximadamente $45 \%$ das crianças de 4 a 6 anos de idade e $10 \%$ entre 7 e 14 anos que vive em comunidades rurais não frequentavam a escola em 2000. Três em cada dez jovens ou adultos que vivem em áreas rurais eram analfabetos. Uma das principais causas destes números negativos é a inexistência de escolas próximas às residências das pessoas, a falta de transporte escolar, ou devido às condições de vida precárias de suas famílias exigem que eles comecem a trabalhar ou ajudar nas tarefas domésticas em uma idade muito precoce.

A ausência de políticas públicas demonstra o tratamento desigual e discriminatório recebido pela população rural. Esta atitude negligente por parte do Estado tem levado a problemas educacionais de longa data, como o analfabetismo; crianças, adolescentes e jovens fora da escola ou sem escola; discrepâncias entre idade e série, repetição e fracasso; conteúdo inapropriado; problemas com a titulação, salários e carreiras dos professores; e uma oferta de escola que é geralmente reduzida para as quatro primeiras séries do ensino fundamental (ARROYO, 2013).

O movimento "Por uma Educação do Campo" foi criado para fazer frente a esta realidade de abandono por parte do Estado. Este movimento começou a exigir políticas públicas de instituições governamentais, bem como o financiamento para a investigação relacionada com questões educacionais em comunidades rurais. O silêncio, esquecimento, e até mesmo a falta de interesse em comunidades rurais em pesquisas sociais e educacionais é um ponto que estava se tornando preocupante. O movimento de Educação do Campo foi criado para relatar esse silêncio e o esquecimento das instituições governamentais, instituições de investigação de financiamento, programas de pós-graduação e estudiosos que estudam as questões sociais e educacionais (ARROYO, 2004).

A exclusão social e educacional dos habitantes das comunidades rurais tem de ser entendido historicamente. No Brasil, a força da ideologia dominante, que foi composta por oligarquias agrárias que prevalecem no país desde os tempos coloniais, tem defendido que era inútil e supérflua para os camponeses aprender a ler e escrever. $O$ argumento por trás disso era que a natureza do trabalho rural (produção de alimentos pelo cultivo da terra para sua subsistência e vender o excedente para a população urbana) não requer qualquer formação escolar. O próprio modo de vida dos camponeses era, a priori, a razão para negar-lhes o acesso à educação (ARROYO, 2004; CAMACHO, 2014).

Apesar de a educação ser reconhecida como um direito humano desde os anos $1980 \mathrm{e}$ que a promoção de uma educação de alta qualidade é o segundo dentre os oito objetivos para o desenvolvimento no milênio para uma sociedade mais justa e sustentável (PNUD, 2014), este reconhecimento não atingiu áreas rurais brasileiras. Moradores de comunidades rurais foram totalmente excluídos desta conquista; este direito só manteve-se no nível abstrato do conceito de cidadania e não atendeu as necessidades específicas e concretas da realidade das comunidades rurais (ARROYO, 2004; CAMACHO et al., 2015). Portanto, a Educação do Campo é uma condição fundamental para que a população rural possa exercer sua cidadania (FERNANDES; MOLINA, 2004). 
Em suma, a marginalização social e educacional vivida pelos moradores das comunidades rurais, devido a falta de políticas públicas voltadas para a sua realidade, engendrou a emergência de lutas de sujeitos coletivos que reagiram diante dessas situações sociais. Dentre estas lutas, destaca-se: a luta pela terra e pela reforma agrária que desencadeou a luta pela Educação do Campo (CAMACHO et al., 2015).

\section{O PROGRAMA NACIONAL DE EDUCAÇÃO NA REFORMA AGRÁRIA - PRONERA}

A história da Educação do Campo está diretamente relacionada à consolidação de uma política pública, ao passo que a primeira grande conquista na Educação do Campo foi o PRONERA. De acordo com Molina (2004), o PRONERA é o pilar teórico e prático da Educação do Campo. O PRONERA tem como objetivo a criação de uma educação que está devidamente adaptado à lógica do trabalho e da cultura no campo, bem como a busca de outra forma de desenvolvimento mais sustentável socialmente e ambientalmente. No PRONERA, as práticas educativas envolvem, os seus sujeitos, ao seu território, a sua forma de organização do trabalho, e a sua cultura, buscando o estabelecimento de outro modelo de desenvolvimento, que seja socialmente justo e ecologicamente sustentável.

De acordo com o Manual de Operação do PRONERA (2011), o PRONERA é uma política pública cujo principal objetivo é fortalecer os territórios rurais em todas as suas dimensões: ambiental, econômica, social, política, cultural e ética. O programa foi criado em 1998 como resultado do esforço feito por representações de movimentos sociais e sindicatos camponeses. A criação deste programa permitiu milhares de trabalhadores, jovens e adultos das áreas de reforma agrária, acessarem o seu direito aos diferentes níveis de ensino.

A Conferência Nacional da Educação Básica do Campo ocorreu em 1998. O objetivo dessa conferência foi o de sensibilizar os órgãos governamentais e a sociedade, em geral, sobre a importância da implementação de políticas públicas de educação adequadas às especificidades das populações do campo (CAMACHO, 2014; CAMACHO et al., 2015).

O PRONERA compreende hoje as ações de alfabetização de jovens e adultos; escolarização nos níveis fundamental, médio, superior e pós-graduação; formação continuada de professores; formação técnico-profissional para a saúde; a comunicação; a produção agropecuária e a gestão do empreendimento rural. Todas estas modalidades de educação estão pautadas em metodologias de ensino adequadas a realidade sociocultural do campo (ANDRADE; DI PIERRO, 2004).

Para a atualização dos dados, o PRONERA lançou a Segunda Pesquisa Nacional de Educação na Reforma Agrária (II PNERA). Esta foi uma pesquisa realizada em parceria com o Instituto Nacional de Estudos e Pesquisa Anísio Teixeira (MEC-INEP) e o Instituto de Pesquisas Aplicadas (IPEA). A pesquisa teve como objetivo caracterizar a demanda educacional e diagnosticar a situação do ensino ofertado nos assentamentos da Reforma Agrária. O resultado da pesquisa é que no período entre 1998 a 2011 foram realizados 320 cursos do PRONERA por meio de 82 instituições de ensino em todo o país, sendo 167 de Educação de Jovens e Adultos Fundamental, 99 de nível Médio e 54 de nível Superior. Os cursos foram realizados em 880 municípios, em todas as unidades da federação (MST, 2015). Vejamos a Figura 1:

Figura 1: Cursos do PRONERA por município de realização (1998-2011) 


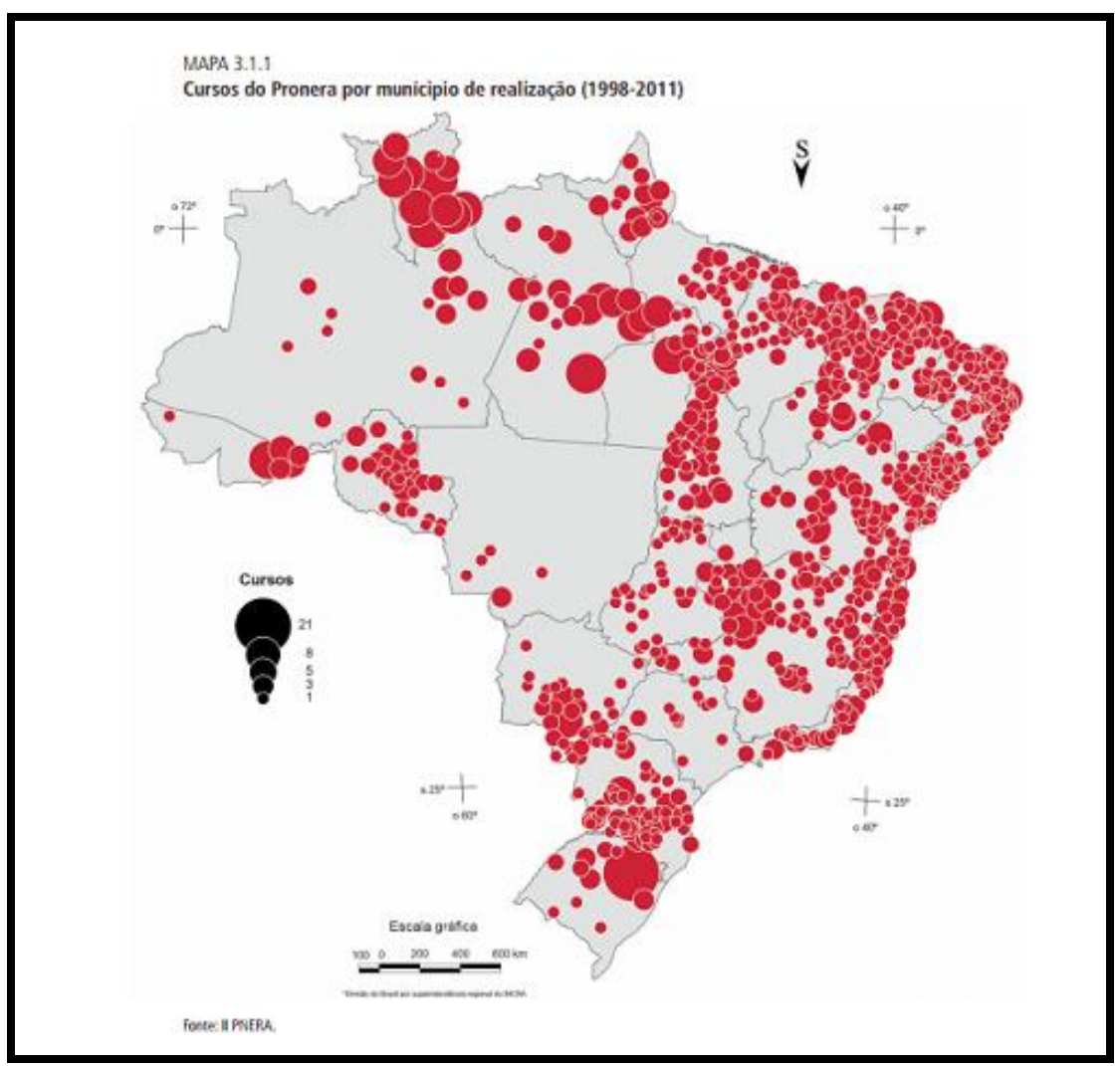

Fonte: II PNERA, 2015.

Em termos de política pública específica, por meio da interação com os movimentos sociais camponeses, a experiência do PRONERA conseguiu se relacionar com a extrema diversidade de situações presentes no campo brasileiro. Diversidade esta que envolve desde a heterogeneidade dos sujeitos sociais do campo, bem como a diversidade das condições culturais, ambientais, geográficas e de organização da produção agrícola. Esta característica do PRONERA somente foi possível devido à interlocução direta que foi travada com os protagonistas deste processo (MOLINA, 2004).

O processo para a aprovação dos projetos é feito da seguinte maneira, as instituições de ensino encaminham o projeto para a Superintendência Regional do INCRA, onde a equipe do PRONERA o avaliará. Depois, o projeto é encaminhado à Coordenação-Geral de Educação do Campo e Cidadania para análise da Comissão Pedagógica Nacional (CPN) (BRASIL, 2011). A Comissão Pedagógica Nacional cuida para que os projetos se orientem por cinco princípios fundamentais que compõe o PRONERA: $\boldsymbol{a}$ inclusão, $\boldsymbol{a}$ participação, $\boldsymbol{a}$ interatividade, $\boldsymbol{a}$ multiplicação e a parceria (ANDRADE; DI PIERRO, 2004).

A inclusão é o princípio que defende a ampliação das condições de acesso à educação; $A$ participação é a garantia que os beneficiários e seus parceiros têm participarem da elaboração, execução e avaliação dos projetos; A interatividade diz respeito à forma como as parcerias entre órgãos governamentais, instituições de ensino superior, movimentos sociais e sindicais e comunidades assentadas estabelecem um diálogo permanente; A multiplicação diz respeito à ampliação não só o número de alfabetizados, mas também de monitores, profissionais e agentes mobilizadores que podem dar continuidade aos processos educativos; A parceria é a condição para a realização das ações do PRONERA. São considerados parceiros do programa: as Instituições de ensino, pesquisa e extensão, públicas e privadas sem fins lucrativos e fundações de apoio; as secretarias municipais e estaduais de educação; Os movimentos sociais e sindicais representativos do público beneficiário (BRASIL, 2011).

Os objetivos dos cursos em nível superior do PRONERA são de garantir a formação profissional para qualificar as ações dos sujeitos e disponibilizar, em cada área de Reforma Agrária, 
recursos humanos capacitados que contribuam para o desenvolvimento socialmente justo $\boldsymbol{e}$ ecologicamente sustentável (BRASIL, 2011). Conforme o Manual de Operações do PRONERA: "Os cursos devem possuir uma sólida formação teórica e contemplar as situações da realidade dos assentados a fim de que os educandos encontrem soluções para os problemas e, simultaneamente, capacitem-se". (2011, p. 72, grifo nosso).

A partir dessa compreensão os cursos estão sedimentados em 05 princípios fundamentais referentes à sua proposta pedagógica: a docência como princípio articulador das atividades pedagógicas; a sólida formação teórica; o compromisso profissional com a realidade e a experiência prática como princípio articulador das atividades; a pesquisa como princípio formativo e a educação como estratégia para o desenvolvimento territorial sustentável.

Os conhecimentos adquiridos objetivam sujeitos que auxiliem no desenvolvimento territorial de sua comunidade. A relação com os movimentos sociais camponeses demonstra, entre outros aspectos, as seguintes características dos Cursos: a relação direta estabelecida com a realidade na qual estão vinculados estes sujeitos; o modelo de gestão tripartite que revela o caráter democrático do PRONERA; o contato direto com as necessidades reivindicadas pela sociedade civil organizada; a possibilidade de instrumentalização dos sujeitos para que transformem a sua realidade tendo como veículo um modelo de educação emancipatório; a possibilidade concreta de construção de outra forma de desenvolvimento com sustentabilidade proposta e efetivada por estes sujeitos.

\section{CONSIDERAÇÕES FINAIS}

Os cursos do PRONERA tem a educação como uma estratégia para o desenvolvimento territorial sustentável. A formação técnica e pedagógica do PRONERA permitirá que os estudantes possam contribuir para o desenvolvimento territorial em sua comunidade. A relevância e a legitimidade destas propostas educacionais são legitimadas com a participação de organizações da sociedade civil em movimentos sociais.

\section{REFERÊNCIAS}

ANDRADE, Márcia Regina; DI PIERRO, Maria Clara. A construção de uma política de educação na reforma agrária. In: ANDRADE, Marcia Regina; PIERRÔ, Maria Clara Di; MOLINA, Mônica Castagna; JESUS, Sonia Meire Santos Azevedo de et al (Orgs.). A educação na Reforma Agrária em perspectiva. São Paulo: Ação Educativa; Brasília: PRONERA, 2004. p. 19-54.

ARROYO, Miguel Gonzalez. A educação básica e o movimento social do campo. In: ARROYO, Miguel G.; CALDART, Roseli S.; MOLINA, Mônica C. (Org.). Por uma educação do campo. Petrópolis: Vozes, 2004. p. 67-86.

BRASIL. Ministério do Desenvolvimento Agrário - MDA. Instituto Nacional de Colonização e Reforma Agrária - INCRA. Programa Nacional de Educação na Reforma Agrária (PRONERA). Manual de Operações do Pronera. Brasília: MDA/INCRA, 2011.

CAMACHO, Rodrigo Simão. Paradigmas em disputa na educação do campo. 2014. 806 p. Tese (Doutorado em Geografia) - Faculdade de Ciências e Tecnologia, Universidade Estadual Paulista, Presidente Prudente, 2014.

CAMACHO, Rodrigo Simão et al. Evaluation of the relationship between education and sustainability in peasant movements: the experience of the national education program in agrarian reform. Evaluation and Program Planning, v.1, p.1 - 23, 2015. 
FERNANDES, Bernardo Mançano; MOLINA, Mônica Castagna. O campo da educação do campo. In: MOLINA, Mônica Castagna; JESUS, Sonia Meire Santos Azevedo de (Org.). Por uma educação do campo: contribuições para a construção de um projeto de educação do campo. Brasília: Articulação Nacional "Por Uma Educação do Campo", 2004. p. 53-91. (Por Uma Educação do Campo, 5).

MOLINA, Mônica Castagna. Pronera como construção prática e teórica da educação do campo. In: ANDRADE, Marcia Regina; PIERRÔ, Maria Clara Di; MOLINA, Mônica Castagna; JESUS, Sonia Meire Santos Azevedo de et al (Orgs.). A educação na Reforma Agrária em perspectiva. São Paulo: Ação Educativa; Brasília: PRONERA, 2004. p. 61-85.

PNUD. Sobre o desenvolvimento humano. Disponível em: <http://hdr.undp.org/en/humandev>. Acesso em: 01 nov. 2014. 